02

\title{
Свойства полиимидной пленки после облучения электронным пучком с дозой 1 GGy
}

\author{
(C) П.Б. Сергеев, Н.В. Морозов \\ Физический институт им. П.Н.Лебедева, \\ 119991 Москва, Россия \\ e-mail: psergeev@sci.lebedev.ru
}

Поступила в редакцию 24.09.2018 г.

В окончательной редакции 24.09.2018 г.

Принята к публикации 06.11.2018 г.

\begin{abstract}
Представлены результаты испытания на работоспособность трехслойного разделителя из фольги для сильноточной электронной пушки эксимерного лазера ЭЛА. Разделитель состоял из двух слоев тонкой титановой фольги с полиимидной пленкой между ними. Такая композиция выдержала 5630 импульсов электронного пучка с длительностью $80 \mathrm{~ns}$ и плотностью энергии за импульс около $9 \mathrm{~J} / \mathrm{cm}^{2}$. При этом полиимидная пленка (Dupont Kapton polyimide film) толщиной $38 \mu \mathrm{m}$ подверглась облучению с дозой 1 GGy. Измерено исходное и наведенное поглощение этой пленки в диапазоне от 20 до $0.4 \mu \mathrm{m}$. Механическая прочность облученной пленки на разрыв уменьшилась в 17 раз.
\end{abstract}

DOI: $10.21883 /$ OS.2019.03.47367.282-18

\section{Введение}

Эксимерные лазеры с электронно-пучковым возбуждением (ЭПЛ) на заре своего рождения около 40 лет назад показали впечатляющие результаты по эффективности, энергии генерации и длинам волн излучения в УФ и ВУФ диапазонах [1-4]. Несмотря на это, они и сейчас еще не вышли за стены лабораторий. Причин здесь много. Одна из них - низкие ресурсные возможности неотьемлемого элемента таких установок, разделительной фольги $[4,5]$. Через нее электронный пучок (ЭП) из вакуумного объема электронной пушки вводится в лазерную камеру с газами при давлении от $1 \mathrm{~atm}$ и более.

В эксимерных лазерах используются мощные сильноточные импульсные ЭП с энергиями электронов от $300 \mathrm{keV}$ и выше, с сечениями от 0.01 до $\sim 1 \mathrm{~m}^{2}$ и длительностями $\sim 100 \mathrm{~ns}$. Плотности энергии ЭП на разделителе достигают $\sim 5-10 \mathrm{~J} / \mathrm{cm}^{2}$. При этом фольга должна быть максимально прозрачной для ЭП, а значит, максимально легкой и тонкой. Она должна выдерживать как можно большее число импульсов ЭП, от $\sim 10^{4}$ и выше, в зависимости от возможного предназначения технологических установок. Это ключевой параметр, определяющий перспективы использования данного вида лазеров.

Для исследования эксимерных лазеров с электроннопучковым возбуждением в Отделении квантовой радиофизики ФИАН в начале 80-х годов была создана „Ускорительная лазерная установка ЭЛ-1“ $[3,4]$, которая сейчас называется ЭЛА [6].

Как показал опыт работы этой и других установок, титановая и алюмобериллиевая фольга лучше всех выносит жесткие условия радиационной и механической нагрузки [4-6]. Но даже толстая однослойная фольга из данных материалов с толщиной до $50 \mu \mathrm{m}$ выдер- живают 100 импульсов ЭП до прорыва. Причина прорывов - бомбардировка быстрыми микрочастицами, возникающими в плазме взрывоэмиссионного катода и ускоряющимися в высоковольтном промежутке.

Повышения ресурса разделителя на установке ЭЛА почти на два порядка удалось достичь на трехслойной комбинации двух слоев титановой фольги толщиной 14-20 $\mu \mathrm{m}$ и полиимидной пленки в $38 \mu \mathrm{m}$ между ними $[4,6]$. Такая пленка (Dupont Kapton polyimide film [7]) была приобретена в середине 80-х годов прошлого века и использовалась до настоящего времени. Фольга и пленка по контуру вблизи торцов склеивались вакуумной смазкой. Этим обеспечивается сохранение вакуума в электронной пушке при прорыве даже пары слоев.

За длительный срок эксплуатации установки ЭЛА с трехслойным разделителем проверялись различные полимерные пленки: полиэтиленовые, тефлоновые, полиимидные Образцы первых двух типов пленок в прямом смысле рассыпались после нескольких десятков импульсов ЭП. И только полиимидные пленки в трехслойном разделителе сохраняли свою целостность даже после нескольких тысяч импульсов ЭП $[4,6]$.

Уникальный комплекс высоких прочностных, электрических, радиационных и температурных свойств полиимидных материалов, в том числе и пленочных, хорошо известен и широко используется в современной технике [7-10]. Однако радиационные свойства полиимидных пленок при облучении электронным пучком в литературе отражены лишь при дозах до $10^{8} \mathrm{~Gy}[7,9,10]$. А как же они ведут себя при более высоких дозах? Есть ли предел в радиационной прочности полиимидных пленок и насколько он определяет ресурсные возможности трехслойных разделителей в электронных пушках эксимерных ЭПЛ? Целью настоящей работы и был поиск ответов на данные вопросы. Эти ответы важны не только 
для понимания проблем физики эксимерных ЭПЛ, но и для оценки сроков возможной работы полиимидных пленок во многих других экстремальных условиях радиационного облучения, в частности, космического $[9,10]$.

\section{Электронная пушка установки ЭЛА и дозовые нагрузки на ее разделитель}

Установка ЭЛА - это модернизированная установка ЭЛ-1, подробно описанная в [3,4]. Модернизации подверглись конструкции некоторых разрядников и изоляторов установки, что не изменило принцип ее работы, но повысило ее энергетические и ресурсные возможности. Поэтому здесь будут представлены лишь некоторые детали конструкции установки ЭЛА, которые важны для понимания условий испытания полиимидных пленок.

Сильноточная автоэмиссионная электронная пушка установки ЭЛА - это вакуумный диод с острийным катодом размером $4 \times 22 \mathrm{~cm}^{2}$. Остриями являются торцы полосок медной фольги толщиной $50 \mu \mathrm{m}$, расположенные поперек длины катода с шагом $2 \mathrm{~mm}$. Анодом электронной пушки является разделитель. Он крепится на протекторе - жесткой ребристой стальной структуре, принимающей на себя давление газа в лазерной камере, а при ее отсутствии - давление воздуха. Размеры выходного окна протектора $5 \times 24 \mathrm{~cm}^{2}$. Его геометрическая прозрачность для ЭП составляет около 70\%.

Напряжение на катоде электронной пушки появляется при его подключении к заряженной коаксиальной формирующей линии (ФЛ) через масляный разрядник $[3,4,6]$. В качестве диэлектрика в ФЛ используется деионизованная дистиллированная вода. Длина ФЛ равна $1.6 \mathrm{~m}$. Ее внутренний электрод имеет диаметр 104, а внешний - $280 \mathrm{~mm}$. При таких габаритах емкость ФЛ равна $7 \mathrm{nF}$, а волновое сопротивление - $7 \Omega$. При работе на согласованную нагрузку длительность импульса тока ФЛ равна 80 ns. Рабочий заряд ФЛ варьируется около $600-650 \mathrm{kV}$, а запасаемая в ней энергия — около $1.4 \mathrm{~kJ}$. Напряжение на катоде в этом режиме близко к $300 \mathrm{kV}$, а полный ток ЭП достигает $40 \mathrm{kA}$. За день на установке можно делать до 150 выстрелов с частотой около $5 \mathrm{mHz}$.

Ключевой характеристикой радиационной нагрузки на полимерную пленку, помещаемую между слоями титановой фольги, является поглощенная доза за импульс. Данная величина определялась путем прямого измерения ослабления плотности энергии ЭП, прошедшего через фольгу или пленку различной толщины. В этих экспериментах при снятой лазерной камере электронный пучок выводился на воздух.

Для измерения энергии ЭП использовался калориметр БКДМ [4,6], приемной площадкой которого является алюминиевая пластина толщиной $0.8 \mathrm{~mm}$ и диаметром $16 \mathrm{~cm}$. Калориметр устанавливался за диафрагмой, пропускавшей на него половину всего ЭП с площадью сечения $5 \times 12 \mathrm{~cm}^{2}$. Диафрагма из винипластовой пластины стояла на расстоянии $5 \mathrm{~mm}$ от разделителя электронной пушки. В данных экспериментах измерялась средняя энергия ЭП за серию из 10-15 импульсов при разной комбинации слоев раздела.

При обычном режиме заряда ФЛ $\sim 600 \mathrm{kV}$ через одиночную титановую фольгу толщиной $14 \mu \mathrm{m}$ в воздух за импульс выходит до $500 \mathrm{~J}$ энергии ЭП. Добавление полиимидной пленки толщиной $t_{p}=38 \mu \mathrm{m}$ и еще одного слоя титановой фольги снижает выводимую энергию ЭП почти до $300 \mathrm{~J}$. Эти результаты позволяют рассчитать среднюю за импульс поглощенную в пленке дозу. С учетом неоднородности распределения плотности энергии ЭП по сечению фольги и потерь на ребрах протектоpa [4] в ее центральной области шириной около $2 \mathrm{~cm}$ поглощенная доза достигает $1.7 \cdot 10^{5} \mathrm{~Gy}$. Погрешность определения данного значения достигает 30\%. Оценка потерь энергии электронного пучка в первом слое титановой фольги позволяет оценить и максимальное значение плотности его энергии на входной поверхности разделителя. Она достигает $9 \mathrm{~J} / \mathrm{cm}^{2}$.

Максимальная мощность поглощенной дозы в течение импульса длительностью $80 \mathrm{~ns}$ находится на уровне $2 \cdot 10^{12} \mathrm{~Gy} / \mathrm{s}$. При таком электронном облучении слои титановой фольги и полиимидная пленка между ними в конце импульса ЭП нагреваются примерно на $200^{\circ} \mathrm{C}$.

\section{Характеристики полиимидной пленки после электронного облучения}

При проведении на установке ЭЛА экспериментов по изучению радиационной прочности оптических материалов (ОМ) под действием ЭП [11] было сделано около 30000 импульсов. В этих экспериментах один из трехслойных разделителей выдержал 5630 импульсов ЭП [6]. Они были выполнены за 68 рабочих дней в течение 13 месяцев. Такая прерывистая работа была обусловлена тем, что примерно после недели работы по облучению образцов ОМ еще 3-4 недели тратились на их спектральное обследование.

С учетом дозовой нагрузки на разделитель за импульс и количества сделанных 5630 импульсов получается, что в этом случае полиимидная пленка в центральной области подверглась облучению с дозой на уровне $10^{9} \mathrm{~Gy} \equiv 1 \mathrm{GGy}$. Такая дозовая нагрузка на порядок превышает цифры, которые приводятся производителем данной пленки и другими источниками $[7,9,10]$. Это и стимулировало детальное обследование пленки, облученной ЭП с такой рекордной дозой.

На рис. 1 представлена фотография трех слоев разделителя установки ЭЛА, выдержавшей 5630 импульсов. Первая титановая фольга (со стороны катода электронной пушки) - нижняя на рис. 1. Она испещрена множеством отверстий с размерами от $\sim 0.1$ до $4-5 \mathrm{~mm}$, число которых превышает 500. Отметим, что при однослойной разделительной фольге даже одно микроотверстие приводит к потере вакуума в электронной пушке. 


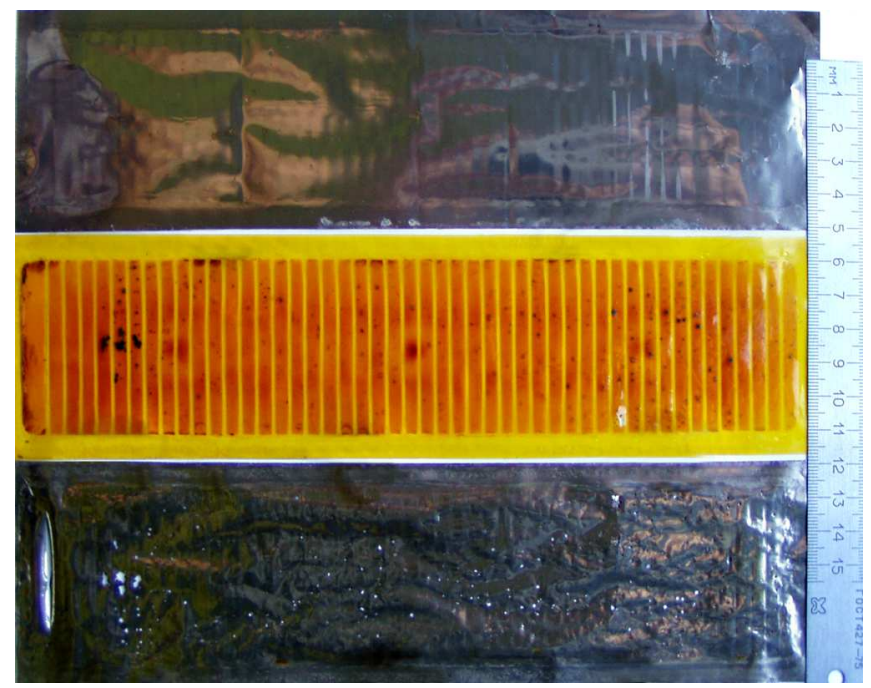

Рис. 1. Фотография разделенных слоев трехслойного разделителя. Нижняя титановая фольга была обращена к катоду, средняя - полиимидная пленка, верхняя - наружная Ті фольга.

Между слоями титановой фольги на рис. 1 расположена полиимидная пленка. На ней четко видны полосы от ребер жесткости протектора - стальных проволочек толщиной $2 \mathrm{~mm}$. В области прохождения электронного пучка полиимидная пленка поменяла цвет: из светложелтой она стала коричневой. Черные точки и области с размерами более $1 \mathrm{~mm}$ на пленке расположены за соответствующими отверстиями в первой фольге. Здесь дозовые нагрузки на пленку могут до двух раз превышать средние значения. Оценить их точнее сложно, так как не известен момент образования отверстий. При этом ни в коричневых, ни даже в черных областях визуально прорывов полиимидной пленки не наблюдалось.

Верхняя титановая фольга на рис. 1 прикрывала полиимидную пленку со стороны воздуха. Визуально какихлибо ее повреждений, приведших к потере вакуума в электронной пушке после 5630-го импульса, не видно. Этот результат ярко демонстрирует живучесть многослойного варианта разделителя электронных пушек $[4,6]$.

Изменение цвета облученных участков полиимидной пленки указывает на изменение ее спектральных характеристик. Поэтому облученная и необлученная пленки были обследованы на спектрофотометрах: Hitachi $\mathrm{U}-3900$ в диапазоне длин волн $\lambda$ от 0.19 до $0.8 \mu \mathrm{m}$, Cary 5000 в области $0.8-3.3 \mu \mathrm{m}$ и в инфракрасной области от $v=500$ до $5000 \mathrm{~cm}^{-1}$ на фурье-спектрометре ФСМ 2201. Использование волнового числа (v) вместо длины волны в последнем случае было обусловлено традиционным видом представления спектральных данных в этом диапазоне.

Спектры пропускания $(T)$ пленок регистрировались в цифровом формате с шагом $1 \mathrm{~nm}$ на Hitachi U-3900 и около $0.5 \mathrm{~nm}$ на других приборах. Показания двух последних приборов „сшивались“ в точке $2.6 \mu \mathrm{m}$ $\left(3846 \mathrm{~cm}^{-1}\right)$. Здесь разброс в измеренных значениях $T$ на разных приборах у обеих пленок был минимален и составлял около $1 \%$. На этом же уровне была ошибка измерений в точке $0.8 \mu \mathrm{m}$, где стыковались показания Hitachi U-3900 и Cary 5000. Результатом всех этих процедур стали спектры пропускания исходной и облученной электронным пучком с дозой 1 GGy полиимидной пленки толщиной $38 \mu \mathrm{m}$. Разные участки этих спектров представлены на рис. 2 и 4, $a$. Отметим, что верхнее значение волнового числа $v$ на рис. 4 , равное $1900 \mathrm{~cm}^{-1}$, соответствует $\lambda$ излучения $5.26 \mu \mathrm{m}$. Это обеспечивает небольшое перекрытие со спектром $T(\lambda)$ на рис. 2.

Обработка цифровой таблицы данных по $T(\lambda)$ на основе соотношения (2) позволяет получить информацию и о поглощении пленок $(\alpha)$ до и после облучения. Выражение $(2)$ легко получается из известного соотношения (1) для пропускания пластин с поглощением

$$
\begin{gathered}
T=(1-R)^{2} \exp \left(-\alpha t_{p}\right), \\
\alpha=\left(1 / t_{p}\right)[\ln (1 / T)+2 \ln (1-R)] \approx\left(1 / t_{p}\right)[\ln (1 / T)-2 R] .
\end{gathered}
$$

В данных выражениях величина $R$ - это коэффициент отражения излучения от грани пленки, $t_{p}=38 \mu \mathrm{m}-$ толщина пленок. Согласно [7], величина коэффициента преломления на $\lambda=589 \mathrm{~nm}$ равна 1.7 , а, значит,
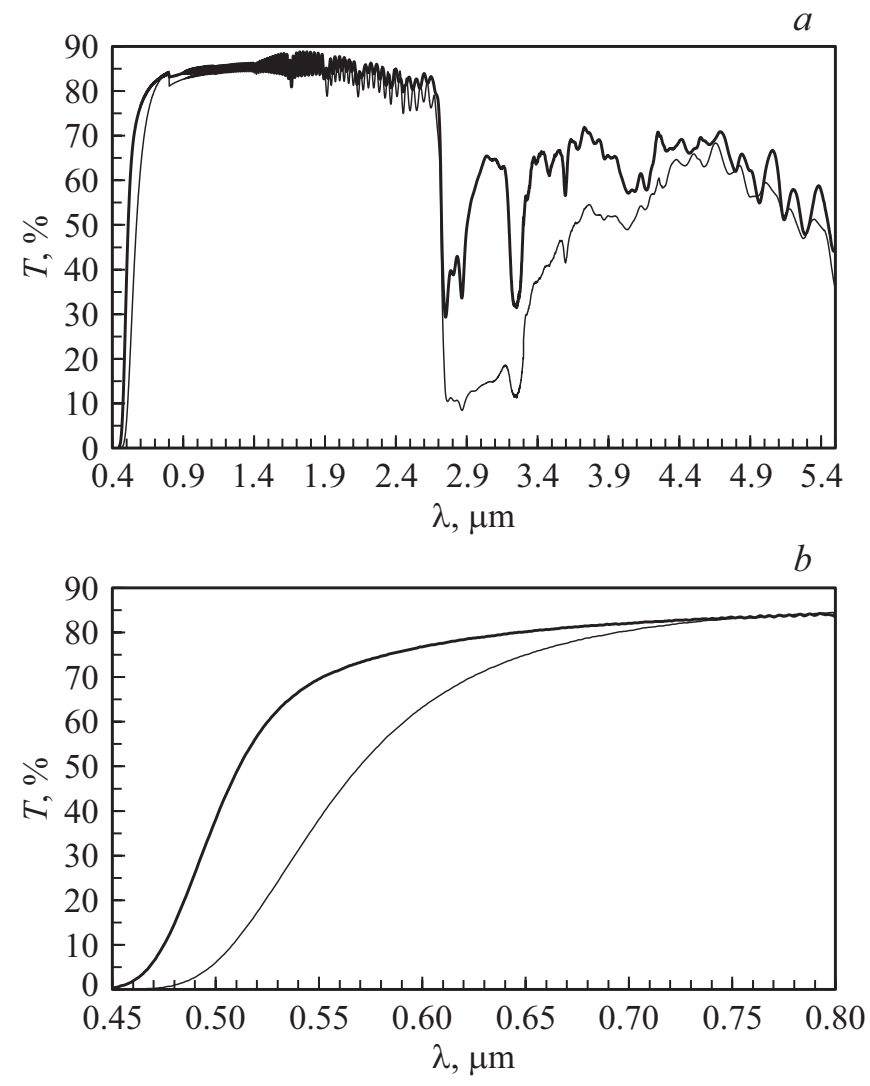

Рис. 2. Пропускание полиимидной пленки толщиной $38 \mu \mathrm{m}$ до (толстая линия) и после облучения электронным пучком с дозой 1 GGy (тонкая линия) в разных областях спектра. 

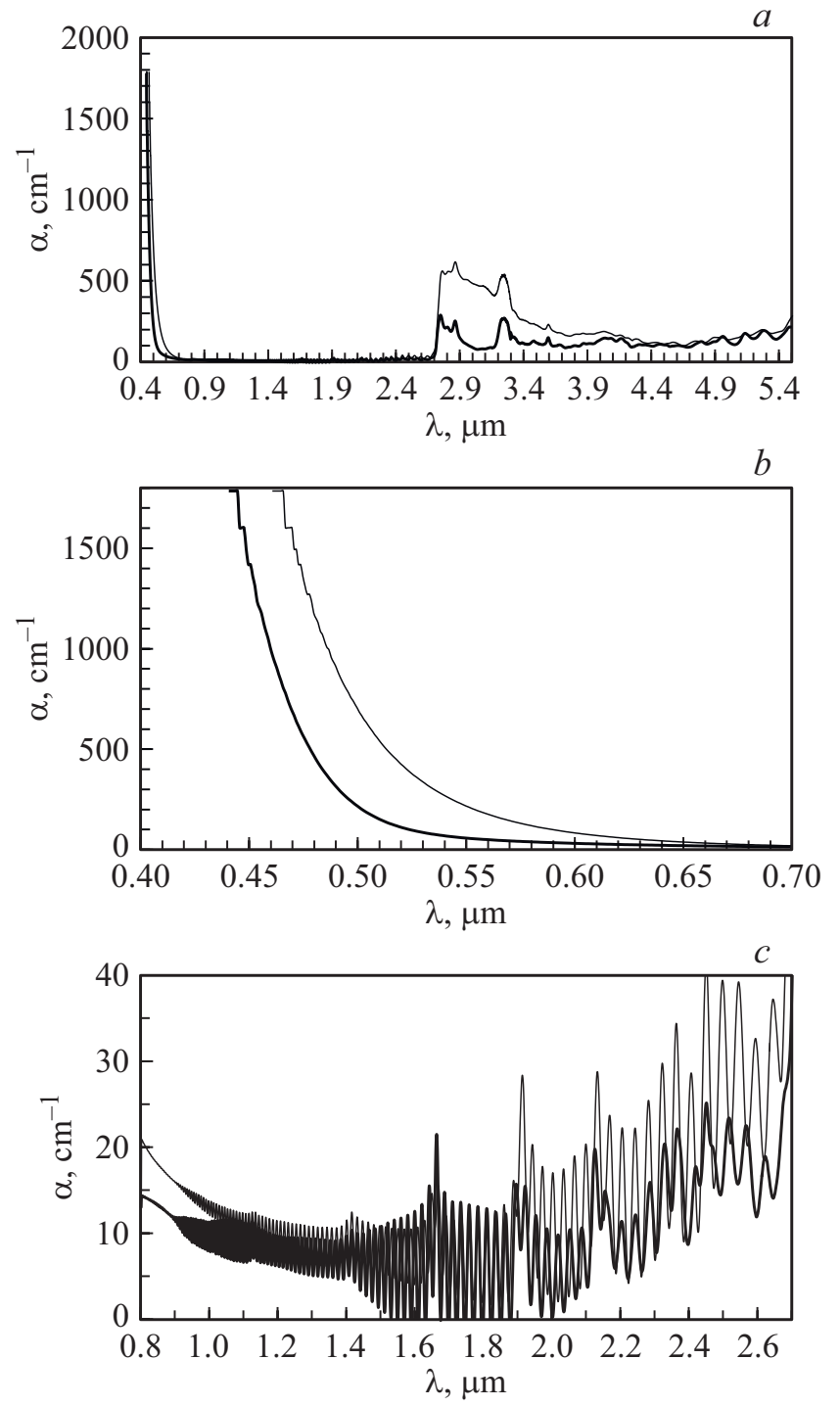

Рис. 3. Спектры поглощения полиимидной пленки толщиной $38 \mu \mathrm{m}$ до (толстая линия) и после облучения электронным пучком с дозой 1 GGy (тонкая линия) с разной детализацией.

$R \approx 0.067$. Это значение и применялось при расчете на основе (2) коэффициентов поглощения пленок в области от 0.44 до $5.5 \mu \mathrm{m}$ (рис. 3). В более длинноволновой области величина $R$ принималась равной 0 . При значениях $\ln (1 / T) \sim 1$ в этой области такое допущение может приводить к завышению величины $\alpha$ не более чем на $20 \%$. Разные участки полученных таким образом спектров поглощения полиимидных пленок до и после электронного облучения представлены на рис. 3 и $4, b$.

Отметим кратко основные изменения спектров $T$ и $\alpha$ облученной с дозой $1 \mathrm{GGy}$ полиимидной пленки по сравнению с необлученной. Электронное облучение привело к смещению коротковолновой границы пропускания пленки примерно с 0.44 до $0.46 \mu \mathrm{m}$ (рис. $2, a$ ). При этом ее поглощение в области $0.46-0.6 \mu \mathrm{m}$ повысилось примерно в 2 раза (рис. $3, b$ ). В области $0.7-2.7 \mu \mathrm{m}$ исходное поглощение полиимидной пленки наименьшее и составляет около $10 \mathrm{~cm}^{-1}$. У облученной пленки оно немного повышается, но не более чем на $5 \mathrm{~cm}^{-1}$ (рис. $3, c)$. Затем идет участок $(\sim 2.75-3.5 \mu \mathrm{m})$, где поглощение увеличивается от 2 до 5 раз (рис. $3, a$ ).

И, наконец, область $500-1900 \mathrm{~cm}^{-1}$ (рис. 4). Здесь исходное пропускание очень низкое и имеет изрезанную структуру с максимальным значением $T$ у некоторых сильных полос около $60 \%$. У облученной пленки пропускание в этих полосах падает примерно вдвое, а поглощение соответственно повышается. Пробелы в спектрах на рис. 4 обусловлены выходом измеряемых приборами значений $T$ за пределы чувствительности $0.5 \%$.

Были измерены также прочностные характеристики полиимидной пленки до и после облучения. Из пленок нарезались полоски шириной $10 \mathrm{~mm}$, которые и испытывались на разрыв. Полоски из необлученной пленки рвались при нагрузке в $50 \mathrm{~N}$, что соответствует прочности на разрыв в $130 \mathrm{MPa}$. Полоски из облученной пленки вырезались вдоль ее максимального размера, т. е. поперек светлых полос от ребер протектора на рис. 1. Полоски с края облученной области, где суммарная поглощенная доза была примерно $0.5 \mathrm{GGy}$, разрушались при нагрузке около $18 \mathrm{~N}$. Это в три раза меньше исходной прочности.
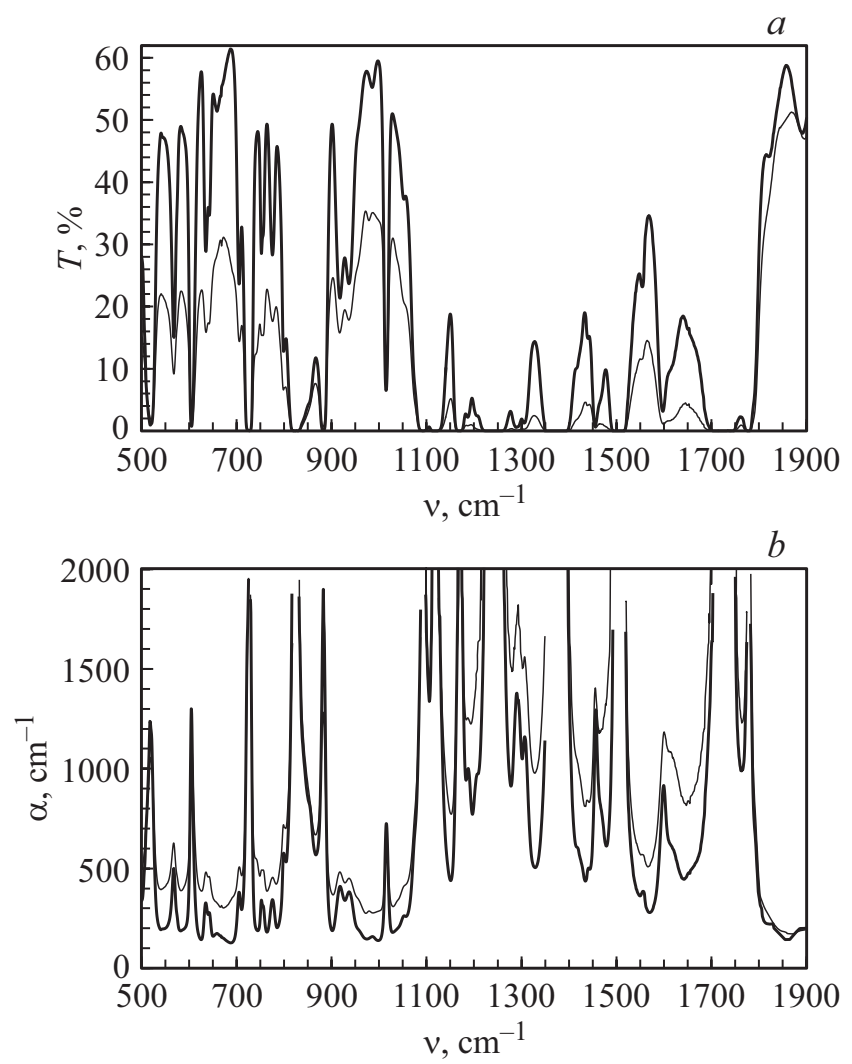

Рис. 4. Пропускание $(a)$ и поглощение $(b)$ в области $500-1900 \mathrm{~cm}^{-1}$ полиимидной пленки до (толстая линия) и после облучения электронным пучком с дозой $1 \mathrm{GGy}$ (тонкая линия). 
Полоски из центральной зоны с дозой облучения 1 GGy рвались при нагрузке в $3 \mathrm{~N}$. Их прочность на разрыв по сравнению с необлученной пленкой упала в 17 раз. Отметим, что иногда при нарезке испытываемых полосок из центральной зоны они ломались по ширине. Такие поломки происходили всегда, если на линии нарезки попадали черные участки пленки, которые сами крошились. Это указывает на полную потерю эластичности полиимидной пленки при уровнях облучения свыше 1 GGy. Очевидно, что ударные механические и/или тепловые нагрузки на такую пленку должны приводить к появлению в ней трещин. Отсюда следует, что дозу в 1 GGy для полиимидных пленок, используемых в качестве разделительного слоя в трехслойных разделителях электронных пушек, можно считать предельной величиной.

\section{Заключение}

Трехслойная композиция разделителя для сильноточной импульсной электронной пушки эксимерного лазера показала высокие ресурсные возможности. При проведении поисковых работ в этом направлении по сути был реализован новый способ исследования радиационной прочности полимерных пленок при воздействии импульсов электронного пучка. Как показано на примере полиимидной пленки, размещавшейся между двух слоев тонкой титановой фольги, этот способ позволяет легко достигать уровней облучения до $10^{9} \mathrm{~Gy}$ и более. Причем такие результаты можно получать как побочный продукт прямого целевого использования имеющихся электронных пушек.

Полученные данные по спектрам поглощения и прочности на разрыв у полиимидной пленки, облученной с дозой $1 \mathrm{GGy,} \mathrm{будут} \mathrm{полезны} \mathrm{при} \mathrm{оценке} \mathrm{ресурсных}$ возможностей изделий, в которых такая пленка работает в жестких радиационных условиях. Так, при использовании полиимидной пленки в многослойных разделителях электронных ускорителей можно принимать дозу на уровне 1 GGy близкой к предельной, свыше которой она теряет эластичность и начинает растрескиваться.

Выражаем благодарность В.И. Козловскому и Я.К. Скасырскому за помощь при проведении спектральных измерений.

\section{Список литературы}

[1] Эксимерные лазеры / Под ред. Ч. Роудза. М.: Мир, 1981. 245 c; Excimer Lasers / Ed. by Ch.K. Rhodes. Berlin, Heidelberg, NY: Springer Verlag, 1979.

[2] Hunter A.M., Hunter R.O., Johnson T.H. // IEEE J. Quantum Electronics. 1986. V. QE-22. N 3. P. 386-404.

[3] Бучнев В.М., Клементов А.Д., Сергеев П.Б. // Квантовая Электроника. 1981. Т. 8. № 6. С. 1235-1240; Buchnev V.M., Klementov A.D., Sergeev P.B. // Soviet J. of Quantum Electronics. 1981. V. 11. N 6. P. 739-741. https://doi.org/10.1070/QE1981v011n06ABEH007040
[4] Sergeev P.B. // J. Russ Laser Res. 1993. V. 14. N 4. P. 237-285. https://doi.org/10.1007/BF01120654

[5] Zvorykin V.D. et al. // Laser and Particle Beams. 2001. V. 19. P. 607-620. doi 10.1017.S0263034601194085

[6] Sergeev P.B., Sergeev A.P. 14th International Symposium on High-Current Electronics. Tomsk, Russia, September 10-15, 2006. // Изв. вузов. Физика. 2006. № 11. Приложение. C. $332-334$.

[7] EC-Kapton-summary-of-properties.pdf. [Электронный peсурс] Режим доступа: www.dupont.com

[8] Hasegawa M., Horie K. // Prog. Polym. Sci. 2001. V. 26. N 2. P. 259-335. https://doi.org/10.1016/S0079-6700(00)00042-3

[9] Михайлин Ю.А. Термоустойчивые полимеры и полимерные материалы. СПб.: Профессия, 2006. 623 с.

[10] Мурадов А.Д., Мукашев К.М., Яр-Мухамедова Г.Ш., Коробова Н.Е. // ЖТФ. 2017. Т. 87. В. 11. С. 1690-1695. doi 10.21883/JTF.2017.11.45131.2174

[11] Сергеев П.Б., Сергеев А.П., Зворыкин В.Д. // Квантовая Электроника. 2007. Т. 37. № 8. C.706-710; Sergeev P.B., Sergeev A.P., Zvorykin V.D. // Quantum Electronics. 2007. V. 37. N 8. P. 706-710. https://doi.org/10.1070/QE2007v037n08ABEH013444 